Digital Press Social Sciences and Humanities

Metaepistemological Analysis of Formation of Knowledge in the Covid-19 Pandemic

Imam Wahyudi and Rangga Kala Mahaswa

Proceeding of 9th International Conference on Nusantara Philosophy (ICNP) Arndt Graf, Fitri Alfariz, M Rodinal Khair Khasri, Rachmad Hidayat, Rokhmat Sairah, Zaid bin Ahmad (eds) 


\title{
Metaepistemological Analysis of Formation of Knowledge in the Covid-19 Pandemic
}

\author{
Imam Wahyudi and Rangga Kala Mahaswa* \\ Faculty of Philosophy, Universitas Gadjah Mada, Yogyakarta, Indonesia \\ *e-mail: rangga.mahaswa@gmail.com
}

\begin{abstract}
Post-truth plays a significant role in forming public social knowledge in the pandemic era, where the flow of information is getting convoluted. This problem is raised in line with the high number of fake news cases, distrust of an expert, massive exchange of information both in real and digital social media, including high case of misinformation, and pseudoscience. This article proposes two general frameworks over the constitution of knowledge in the pandemic era: a naturalistic and social-constructive approach. Naturalism tends to focus its analysis of formation of social knowledge in pandemic on the scientific ground, such as discussion on the ontology of virus whether virus understood as an individual microscopic entity or as a life process. Conversely, the social constructivist approaches in analyzing constitution of knowledge of the pandemics as nothing, but a social construct such as non-natural disasters and public discourse consensus. In one position, naturalism offers an objective and cognitive ground based on scientific consensus, but in another case, social-constructivism also offers an explanatory role such as explaining the human-virus interaction. In order to confront this issue, this article will discuss metaepistemological analysis of the formation of social knowledge based on those two general frameworks and initially propose position under the Epistemological Plurality. Nevertheless, this article still left difficult, especially how to apply epistemic pluralism under practical domain without falling into relativism? Therefore, this article initially opens further philosophical works and discussions to offer a critical epistemological view in forming epistemology of pandemic and maybe as a postpandemic policy consideration.
\end{abstract}

\section{Keywords}

Pandemic, meta-epistemology, social-constructivist, naturalism, post-truth.

\section{Introduction}

The history of humanity has entered the Anthropocene epoch, which made humans as a geological force. There are various theses on the origin of the Anthropocene. The Great Acceleration ( 1950s) is one of the potential candidates for the golden spike of the latest Anthropocene geological time scale. This is indicated by the rate of massive anthropogenic activity, which directly affects changes in the global geological structure (Steffen et al., 2015). So far, the situation is a series of remarkable events where there is an acceleration of global socio-economic trends activities. The most surprising event is the opening of social and natural spaces broadly after colonialism and the second world war.

The global phenomenon of the Covid-19 pandemic signals a natural openness that is fundamental to why the global community is very vulnerable to local-global outbreaks. Also, a global pandemic is challenging to predict when and where the next unpredictable phenomenon will appear. Massive 'humanto-human' zoonotic transmission is increasingly challenging to control at the beginning of the pandemic and reminds us that the Anthropocene is an important part of the global openness of space and boundaries (Kanniah et al., 2020). At the same time, this pandemic has provided a various understanding of our human-nature relations and triggered new biopolitics and social engineering to force social action in the new normal. 
The social lives affected by the pandemic have reached the point of cultural and structural transformation, both micro and macro. Uncertainty and the threat of death cause progressive political decisions in society. They have an inseparable impact at the beginning of the pandemic, emerging culture shocks, and pandemic fatigue issues during the transition phase. It is because people have never experienced this pandemic before.

In a technological society, people always open public debate about the status of the Covid-19 virus to test the truth of this phenomenon. Ironically, during the pandemic, most people use social media to escape, creating new epistemic distractions due to the tremendous uncertainty of information in the digital world. The speed of access and updating of information has influenced the trajectory of public debates. The split of information is getting stronger because there are two positions: the pros and cons, regarding political reality and the knowledge status of the coronavirus. Information uncertainty causes ambiguity of belief. On the other hand, post-truths like black holes absorb information inequality, causing a split between scientific-based knowledge or knowledge that relies on fake news, hoaxes, conspiracies, and even pseudoscience.

\section{Social Constructivism on the Pandemic Understanding}

Epistemology of pandemic based on social construction is the most developed discussion during a critical time. This is due to the closeness between the impact of the Covid-19 pandemic and political policies during the pandemic. The importance of epistemic humility status (Parviainen, 2020) during a pandemic is a form of epistemic humility (Parviainen et al., 2021). In addition, social epistemologists play a significant role in formulating an epistemic attitude view that manages the increasingly widespread ignorance and insecurity caused by the slowness of a public policy being taken.

A pandemic can also be understood as a catastrophic epistemology formulation (Beer \& Hariman, 2020). Beer and Hariman (2020) claim that the Covid-19 pandemic crisis has not only challenged public health policies and tested epidemiologists but has also become an epistemological crisis. This crisis involves the inability and limited knowledge of what is real and the limited imagination to structural change during a catastrophic pandemic. Critical responses are also needed to test the validity of scientific knowledge about the Covid-19 pandemic. There is a need for constructive criticism regarding scientific thinking and practice that can be translated into public health policies and consensus during and after the pandemic (Fortaleza, 2021). In addition, the historical and political explanation of microbial epistemology is a unique topic of discussion. It has developed since the early 20th century, which has built an epistemic understanding behind the relationship between humans, microbes, and viruses and influences the sociocultural life of society (D'Abramo \& Neumeyer, 2020). Hurlbut (2017) also mentioned how Indonesia's scientific data access policy was during the H5N1 virus pandemic (Hurlbut, 2017). The relationship between political norms and governance of pandemic risk is a controversial topic that discusses obligations, genome data, and sovereignty of a country with world health authorities. The issue of epistemology of pandemic can be traced from several cases before the global Covid-19 pandemic.

In the Covid-19 pandemic, sources of knowledge can emerge from social media and other nonscientific channels. Pandemic shifts a political epistemology in the post-digital and post-truth era, it has pushed people's conventional knowledge to switch to digital knowledge of the community to reduce the level of risk during a pandemic (Coeckelbergh, 2020). Also, Fuller (2020) sees pandemics in the posttruth world as a 'quantum epistemology,' which has never been sought before but is then investigated to confirm its existence (Fuller, 2020). The importance of understanding current information as a form of pandemic knowledge in the context of global epidemiology, mitigation strategies, clinical features, pathogenesis, immune responses, and the latest developments in vaccines (Singh et al., 2021). Timmermann's research (2020) shows that the Covid-19 pandemic has caused the emergence of a new poverty-epistemological issue as well as epistemic ignorance (Timmermann, 2020). In addition, a review of epistemic responsibilities can play a role in dealing with the Covid-19 pandemic to build the correct consensus (Levy \& Savulescu, 2020).

In our view, the epistemology of pandemic approach based on social construction is more focused on public consensus, the social impact of the pandemic, and the social interaction of epistemology in response to changes in public relations in the face of a pandemic. This view has a unique characteristic that is social, relative, and rich in alternative discussions and has an impact on a significant pandemic policy. 


\section{Role of Naturalism on the Pandemic Understanding}

Metaepistemologically, the constitution of knowledge of the pandemics in naturalism discourse pays attention to the ontology of viruses and the philosophy of biology. Viruses are generally accepted for their existence when certain symptoms of a disease appear to the surface. There are various approaches to identifying the ontological status of viruses and how viruses are understood, such as Dupré and Guttinger (2016), who view viruses not as individual microscopic entities but as living processes. Similarly, social anthropologist Lowe (2010) explains that viruses are described as dynamic and interacting processes like 'clouds' or swarms rather than as entities. On the other hand, there is also a view that has a strong tendency to link viruses to diseases that are dangerous to humans, along with a strong tendency not to think of viruses as living things which limits scientists' ability to appreciate the ecological role of viruses and their role in the evolution of humans and other species. This is because, in the pandemic phenomenon, there are at least four stages of the pathogen pyramid, namely the first level of exposure (direct contact between viruses and humans); the second level is infection; the third is transmission, the last is the spread of the virus from a local outbreak to a global pandemic. These four stages provide epistemic justification that there is a natural dimension when the process of a pandemic phenomenon occurs, from the virus as the primary agent triggering the pandemic.

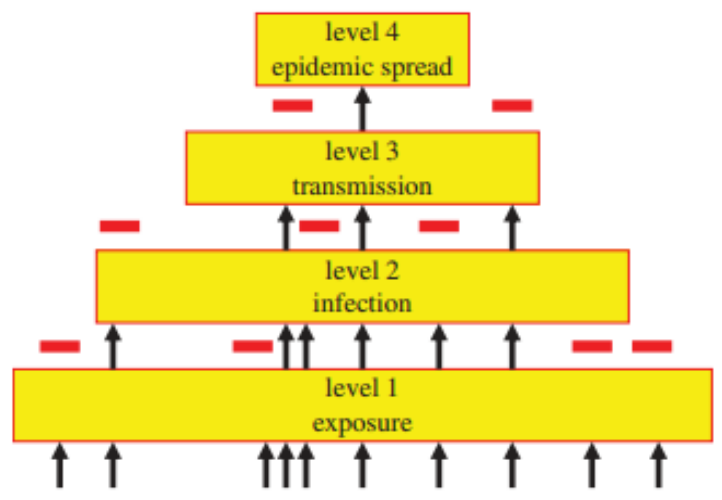

Fig 1. Pathogens Pyramid (Woolhouse et al., 2012)

Identifying viruses as individual microscopic entities facilitates the research step by establishing a precise reference point of departure is a scientific research process. On the other hand, the determination of a definitive explanation on a causal basis of a particular phenomenon. For example, an infection with a flu symptom can be explained by a virus that causes the flu symptom. The assumption of virus identification as a microscopic individual entity is not only a certain methodological assumption that is informative in value, in the sense that it is not only a clear starting point in the process of scientific investigation and as a clear definitive basis for a particular symptom, but also contains an underlying philosophical assumption: that an entity contains a clear boundary. There is an intrinsic feature possessed by the entity (Dupré \& Guttinger, 2016). Thus, the virus is offered as a living process.

This limitation is motivated by the fact that viruses operate differently compared to things-views that tend to be oriented towards specific targets. To illustrate the difference between the two views, Guttinger (2020) explains that the best way to look at it is in the case of reproductive success (Guttinger, 2020). In things-view, reproductive success is explained through reproductive machinery, such as how viral enzymes replicate the genome and to what extent they can adapt in specific contexts. In other words, a suitable reproductive machine with a much higher rate of reproductive success has conformity.

However, based on new findings in virology, viruses multiply and reproduce depict different viral compatibility. Other studies have shown that for many viruses, including influenza, HIV, or hepatitis, the viral population within an organism represents a highly diverse and, importantly, dynamic system. Rather than forming a collection of identical particles, the viruses form what researchers commonly refer to as clouds mutant. The swarm then develops and replicates within the infected organism as described by Lauring and Andino (2010) based on the quasispecies theory of viruses where, as in viruses that are classified as medically significant, such as HIV, hepatitis C virus, and influenza, they replicate with very high mutation rates and show significant genetic diversity (Lauring \& Andino, 2010). This diversity within a swarm allows viral populations to quickly adapt to dynamic environments and develop 
resistance to vaccines and antiviral drugs. Through these mutations, the herd composed of diverse genetically related variants interact cooperatively at the functional level and collectively contribute to population characteristics. The herd does not only work as a whole that relies on specific relationships and contexts. How the swarm forms from a single particle is not an intrinsic feature of the virus particle. This process is only one of several factors involved in establishing genetic diversity in viral populations.

The paradigm shift based on these findings requires an approach oriented towards isolated particles based on a certain intrinsic property towards a new way of research in handling viruses in more dynamic and delocalized systems. In other words, rather than focusing on the atomic structure of a virus particle, some scientists find a new way of interfering with the dynamics within the swarm. Intervention against the virus system can be done by increasing mutation rates, such as disrupting the balance in the herd, which will lead to the extinction of the virus. Although this approach has its challenges, according to Guttinger (2020), a focus on swarm dynamics is a strategy that is in line with how viruses act within an infected organism (Guttinger, 2020).

Contrary to previous ideas that focused on studying viruses from a biological perspective, de Chadarevian and Raffaetà (2021) argue that it is not enough to examine viruses simply by combining biological and social paradigms as they are linked (de Chadarevian \& Raffaetà, 2021). Understanding viruses and pandemics also requires considering the dynamic interactions between humans and other species in certain historical settings. On the other hand, it is also necessary to consider the dynamic interactions of humans and other species in specific historical settings that can help us gain valuable and promising insights about how to live humanely in a pandemic and a world that is more than humanoriented or anthropocentrism.

Also, Napier (2020) explained that Napier argues that there is an assumption of anthropocentrism in the review of viruses through a metaphor where the virus as a living organism attacks humans as its host (Napier, 2020). This paradigm was born because of our inability to involve social science in responding to COVID-19 and how this neglect makes the population in certain circles more vulnerable. Starting from this assumption to challenge the dominant anthropocentric paradigm, a multispecies approach in anthropology is developed to analyze the situation of virus contact with humans in a specific background, not only from the human point of view but also from other species perspectives. Kirksey further described pandemics as a "multispecies assemblage" to highlight the adaptive transformation of the virus in interactions with other life forms (S. E. Kirksey \& Helmreich, 2010). Van Dooren and Kirsey (2020) highlight that when viewed from a different perspective, human political, economic, and ecological life often threatens the original habitat of viruses and sets the stage for the transfer of viruses from animals to human hosts.

\section{Emergence of Post-Truth Issue as Epistemological Instability}

Starting the debate concerning the epistemology of a pandemic, we should note that this article indicates post-truth has a significant role in the formation of public social knowledge regarding the pandemic. The assumption that underlies this is that currently, sources of knowledge can emerge from various channels, mainly social media, digital, random, and anonymous. Post-truth is a challenge because its epistemological grounding is different from the general epistemology. If classical epistemology asks philosophical questions about the status of Justified, Truth, and Belief (JTB), in the Post-truth issue, the epistemic approach becomes Justified, False, and Belief (JFB). Why is that? It is because research on contemporary epistemological open further space for criticism of the meaning of 'what is called knowledge', it becomes a question of theoretical decisions in epistemology as a normative review of the relationship between knowledge, belief, and an action decision. In this study, we add meta-epistemology to answer the main problems in epistemology (Kyriacou \& McKenna, 2018).

Generally, Post-truth deals with various derivatives often found in everyday life, both in real and digital social media, including conspiracy phenomena, hoaxes or fake news, misinformation, and pseudoscience. Post-truth has become one of the strong foundations with the influence of the postmodern version of the truth and its relation to socio-political epistemic (Blackburn, 2021). On the other hand, according to Goldman (2011), some people tend to distrust experts because an expert cannot really guarantee knowledge in the public discourse. The unstable information spread digitally results in unclear information and expertise trusted by the public or social media users. Post-truth politics also opens up opportunities for unequal situations between expert opinions and random opinions from certain groups claiming to be experts to provide the possibility of conspiratorial interpretation of reality and false 
interpretation toward science because the element of emotional impulse is more critical than rationality considerations. The hidden truth often relies on reducing testimony results to experts who only partially explain the truth and are wrapped in a specific ideology.

According to Blackburn (2021), post-truth has a unique epistemological stance but a much different position, and it no longer indicates the objectivity of truth but leads to preferences, persuasion, and emotions, which are understood collectively. In today's digital era, the dissemination of information is very complex; epistemic-conspiratorial tensions reinforce post-truth. Conspiracy theories appear as ignorance or truth that is forced based on what they want to find, not what the truth speaks about. For example, a housewife who does not believe in vaccines tries to find information through a search engine with keywords that are in line with what she is looking for, then the search engine bubble filter will definitely refer to and confirm what she is looking for, like a cycle of preferences support. Thus, Post-truth is a status of truth and a source of truth referred to by a person, affirmation of truth, and validation of knowledge-based on non-objective emotional demands.

Bernecker et al. (2021) reaffirm that the definition of Post-Truth leads to a condition when public opinion is dominated by emotions and personal-shared beliefs rather than objective facts. A kind of epistemic pathology, Post-truth is systematically shaped by irrelevant truth factors and is believed to be the truth of the majority of public opinion and does not care whether a belief in opinion and the emotional foundation of the public corresponds to the truth or not. There are two main factors that posttruth can be realized, namely the existence of irrational public opinion and agents of misinformation. Forming an opinion without proof of truth is clearly irrational because then this epistemic irrationality is simply believed by those who believe in it. This irrationality factor generally consists of individual bias (overconfidence, confirmation bias, narrative bias, emotional bias) and social bias (social identity or group mindset) that play a dominant role in post-truth (Bernecker et al., 2021). However, environmental factors or agents who manipulate evidence can lead to a view of reality which is usually wrapped in fake news or hoaxes. Post-truth, for example, can be traced from several phenomena ranging from information cascade (groups that hide relevant information), filter bubbles (internet algorithms that direct users to specific information), journalistic practices (there is an ambiguous narrative tendency for the public), social media (media dissemination and distribution of fake news), as well as certain ideologies.

Post-Truth epistemology in the context of this research, specifically, refers to the phenomenon of fake news, hoaxes, and conspiracies that have developed since the spread of the global Covid-19 pandemic. The epistemic reason for choosing fake news or conspiracies is because the epistemological basis for testimony is stronger and becomes the main discussion of epistemology of pandemic. Attention to an epistemology of testimony is strong enough to explain the relationship between epistemic status (justification and knowledge) and beliefs formed by someone with what others had said before (testifier/testified). The testimonial epistemology debate raises two main views, namely reductionism and anti-reductionism. Anti-reductionists argue that the norm of truth-telling is standard in society, particular testimonies can be considered trustworthy unless there is reason to question them. While reductionists, on the other hand, public testimony cannot or is difficult to believe in its entirety, each recipient of testimony/testimonials must re-examine previous sources of belief before believing it. However, both views have challenges in today's digital communication era when too many online content sources are anonymous. Truth recipients cannot clearly ascertain who the testifier (truth giver) is if it is random or anonymous (unknown person or $\mathrm{AI} /$ chatbot), moreover, in the source of truth, evidence, honesty, and competence.

At the testimonial level, the next challenge is the message or information shared or forwarded in digital communication via email and social media. As a freedom media in accessing information, social media is a platform that can increase the opportunity to communicate and access information as widely as possible. The epistemology of testimonials in Post-Truth has semantic instability problems, redundancy, and the basis for the credibility and reliability of the information. Post-truth sources can come from ordinary users of social media, mass media, and certain groups that have the characteristics of group polarization, extreme identity, and excessive anxiety about news or truth spread in cyberspace. There are seven dimensions of fake news in the post-truth context, according to Jaster and Lanius (2021), including 1) The truth dimension: fake news is false and misleading; 2) The dimension of deception: news distribution intends to deceive; 3) The bullshit dimension: contributors are indifferent to the truth; 4) Appearance dimension: imitating the 'real' news/truth; 5) Effect: being the centre of attention, because it deceives the audience; 6) Dimensions of virality: to be widely disseminated; 7) The media dimension: a phenomenon that occurs on the internet and social media (Jaster \& Lanius, 2021). Thus, post-truth epistemology has the issue of testimony and verification of truth where a news report or information that does not have any truth has been disseminated to deceive or ignore the truth. 


\section{Challenges in Securing Knowledge}

Furthermore, following on several issues before, this paper can be concluded that at least we found several aspects in the formation of knowledge in this pandemic time, both epistemic instability and semantic instability. First, epistemic instability sees information ambiguity under anonymity and distrust in experts. Semantic instability issues concerning instability of meaning that tends to lead to lies or falsehood. To overcome this problem, at least two meta-epistemological analytical approaches can be used to ensure the validity of knowledge based on the naturalist and socio-constructivist approaches.

Naturalism provides an objective guarantee concerning knowledge grounded under natural facts, obtained in the laboratory research or investigation of virus interaction patterns. Meanwhile, the socioconstructivism views an explanatory basis for information dissemination, the relation and role between humans and viruses as well as information flow patterns, dominated by testimonial and public conversation. However, between naturalism and socio-constructivism, there are very challenging only to accept one side of these approaches. Thinking and building knowledge about pandemic merely based on a social constructivism-oriented will be extremely relativism because it ignores the basis of justification for legitimacy on the basis of truth. Also, leaving the knowledge under a fact-oriented to naturalistic view would be too restrictive.

In this case, the epidemiological model and scientific advice have a very significant influence on the immediate public policy toward lock-down and social restriction to prevent virus spreading, it also offers on the development of post-pandemic strategies in future. According to Adam (2020), scientific model and results during pandemic also have a possibility that there is no guarantee that experts are value-free from 'scientific' biases. In the socio-political space, Lohse and Bschir (2020) criticize the way scienceinformed and guided policy during the pandemic. The government action and policy has been mainly driven by COVID-19 cases and deaths and many of them failed to tackle this situation, like lock-down to protect people in a vulnerable economic, and other social consequences of lock-downs from social inequalities to domestic violence.

Finally, this article proposes an epistemic pluralism approach to reconcile these blind issues between naturalism and socio-constructivism ambition. Adopting epistemic pluralism is the way to rethink that the reality of post-truth also has an essential key in framing current social epistemic understanding about pandemic, but at the same time, semantic and epistemic instability being the hole in-between verifying testimonial notion and unfinished verification of truth. Meanwhile, people need a swift political decisions and social action to prevent this virus. When we wait for the final truth of COVID-19 definition behind naturalism, the outbreak will never be handled in faster way, ironically, when people also depend on public rumours under post-truth information, they will be so far from the real status of pandemic and tend to be more sceptical about virus's relations in the social world. Implementing epistemic pluralism is important to consider various perspectives in political decision making. The further issue is how to implement epistemic pluralism in practical realism, and not trapped into absolute relativism. Therefore, strengthening epistemic pluralism in evidence-for-use-based public health policy needs many more perspectives that can measure realistically about the pandemic prevention and other normative issues during uncertain times.

\section{Conclusion}

In conclusion, in this article, we offer two dominant views in an understanding of pandemic. Naturalism offers an objective and cognitive ground based on scientific consensus. In another case, social constructivism also offers an explanatory role, such as explaining the human-virus interaction. In order to confront this problem, meta-epistemological analysis is important to understand two general frameworks under epistemological plurality. Again, this article still challenges absolute relativism shadowing practical public discussion under instability post-truth information. Therefore, the multi-disciplinary investigation is to provide a multi-layered answer to deepen understanding of potential epistemic shortcomings of securing knowledge under evidence-based public health policy.

Acknowledgements. This article is part of our presentation at the International Conference on Nusantara Philosophy (ICNP) 2021. Some words are part of our future research, and it will be published in a specific journal further. However, we thank the Faculty of Philosophy, which funded our research in the grant scheme called Penelitian Pengembangan Mata Kuliah BPPTN-BH 2021. 


\section{References}

Adam, D. (2020). Modelling The Pandemic: The simulations driving the world's response to COVID-19. Nature, 580(7803), 316-318.

Beer, F. A., \& Hariman, R. (2020). Learning from the Pandemic : Catastrophic Epistemology Learning from the Pandemic: Catastrophic Epistemology Francis A . Beer, University of Colorado, Boulder, beerf@comcast.net; Robert Hariman, Northwestern University, robert.hariman@comcast.net. Social Epistemology Review and Reply Collective, 9(5), 19-28. https://wp.me/P1Bfg0-4Wa.

Bernecker, S., Flowerree, A. K., \& Grundmann, T. (2021). The Epistemology of Fake News. Oxford University Press.

Blackburn, S. (2021). Politics, truth, post-truth, and postmodernism. In The Routledge Handbook of Political Epistemology (pp. 65-73). Routledge.

Coeckelbergh, M. (2020). The postdigital in pandemic times: A comment on the Covid-19 crisis and its political epistemologies. Postdigital Science and Education, 2(3), 547-550.

D'Abramo, F., \& Neumeyer, S. (2020). A historical and political epistemology of microbes. Centaurus, 62(2), 321-330.

de Chadarevian, S., \& Raffaetà, R. (2021). COVID-19: Rethinking the nature of viruses. History and Philosophy of the Life Sciences, 43(1), 1-5.

Dupré, J., \& Guttinger, S. (2016). Viruses as living processes. Studies in History and Philosophy of Science Part C: Studies in History and Philosophy of Biological and Biomedical Sciences, 59, 109-116.

Fortaleza, C. M. C. B. (2021). Emergency science: Epistemological insights on the response to COVID-19 pandemics. Infection Control and Hospital Epidemiology, 42(1), 120-121. https://doi.org/10.1017/ice.2020.209

Fuller, S. (2020). A Post-Truth Proactionary Look at the Pandemic. Postdigital Science and Education, 2(3), 551-555. https://doi.org/10.1007/s42438-020-00124-5

Goldman, A. I. (2011). A guide to social epistemology. Social Epistemology: Essential Readings, 11-37.

Guttinger, S. (2020). A Virus Is Not a Thing, Part 1: The case for a process view of viruses. https://www.lse.ac.uk/philosophy/blog/2020/07/06/a-virus-is-not-a-thing-1/

Hurlbut, J. B. (2017). A science that knows no country: Pandemic preparedness, global risk, sovereign science. Big Data \& Society, 4(2), 2053951717742417.

Jaster, R., \& Lanius, D. (2021). Speaking of Fake News. The Epistemology of Fake News, 19.

Kanniah, K. D., Kamarul Zaman, N. A. F., Kaskaoutis, D. G., \& Latif, M. T. (2020). COVID-19's impact on the atmospheric environment in the Southeast Asia region. Science of The Total Environment, 736, 139658. https://doi.org/https://doi.org/10.1016/j.scitotenv.2020.139658

Kirksey, E. (2020). The emergence of COVID-19: a multispecies story. Anthropology Now, 12(1), 11-16.

Kirksey, S. E., \& Helmreich, S. (2010). The emergence of multispecies ethnography. Cultural Anthropology, 25(4), 545-576.

Kyriacou, C., \& McKenna, R. (2018). Metaepistemology: Realism and Anti-Realism. Springer. 
Lauring, A. S., \& Andino, R. (2010). Quasispecies theory and the behavior of RNA viruses. PLoS Pathogens, 6(7), e1001005.

Levy, N., \& Savulescu, J. (2020). Epistemic responsibility in the face of a pandemic. Journal of Law and the Biosciences, 7(1), lsaa033.

Lohse, S., \& Bschir, K. (2020). The COVID-19 pandemic: a case for epistemic pluralism in public health policy. History and Philosophy of the Life Sciences, 42(4), 1-5.

Parviainen, J. (2020). "We're Flying the Plane While We're Building It": Epistemic Humility and NonKnowledge in Political Decision-Making on COVID-19. Social Epistemology Review and Reply Collective, 9(7), 6-10.

Parviainen, J., Koski, A., \& Torkkola, S. (2021). 'Building a Ship while Sailing It.'Epistemic Humility and the Temporality of Non-knowledge in Political Decision-making on COVID-19. Social Epistemology, 35(3), 232-244.

Singh, R., Kang, A., Luo, X., Jeyanathan, M., Gillgrass, A., Afkhami, S., \& Xing, Z. (2021). COVID-19: Current knowledge in clinical features, immunological responses, and vaccine development. The FASEB Journal, 35(3), e21409.

Steffen, W., Broadgate, W., Deutsch, L., Gaffney, O., \& Ludwig, C. (2015). The trajectory of the Anthropocene: the great acceleration. The Anthropocene Review, 2(1), 81-98.

Timmermann, C. (2020). Epistemic ignorance, poverty and the COVID-19 pandemic. Asian Bioethics Review, 12(4), 519-527.

Woolhouse, M., Scott, F., Hudson, Z., Howey, R., \& Chase-Topping, M. (2012). Human viruses: discovery and emergence. Philosophical Transactions of the Royal Society B: Biological Sciences, 367(1604), 2864-2871. 